\title{
MODELING OF OPTIMAL DESIGN AND MANAGEMENT OF MICRO-IRRIGATION SYSTEM
}

Sharaf, G. A ${ }^{1}$, Azza Hassan ${ }^{2}$ and Hashem Mahmoud ${ }^{3}$

\section{ABSTRACT}

A nonlinear optimization model for design and management of microirrigation system is proposed. The model divides the field into subunits. The decision variables are pipes lengths and diameters (lateral, riser, manifold, auxiliary, submain and main), the total number of subunits, number of sets or shifts operating simultaneously, irrigation time per set, system average operating pressure, pressure at the control head (pump), pump power, emitter average flow rate and total capital cost. The Microsoft Excel Solver tool that applies the Generalized Reduced Gradient (GRG2) nonlinear optimization code was used to solve the optimization problem. The objective function is minimizing the system total cost. Results showed that the cost per unit area increased by increasing the total irrigated area: Meanwhile the total costs increased by increasing the total area in case of irrigating the whole area at once (one shift). The rate of increasing cost depends on the number of shifts, number of sets and number of subunit per set that operate simultaneously. The total costs were affected by the emission uniformity. Results indicated that total cost increased at higher uniformity. This effect increased by decreasing number of shifts.

Keywords: Modeling, Optimization, Micro-irrigation, Management

\section{INTRODUCTION}

major challenge of today's society is to increase food production
and conserve water resources to accommodate tomorrow's
needs. Micro-irrigation is an application system supplying filtered water directly to a plant through an emitter and complex distribution network. The distribution net work is typically subdivided into subunits, each having laterals, manifold, auxiliary, and control unit. The distribution network is divided into subunits for several reasons; increase flexibility in

1- Prof. of Agric. Eng., Dept. of Soil \& Agric. Chemi., Fac. of Agric. Saba basha Alex. Univ.

2- Senior Res. Agric. Eng. Res. Inst. (AEnRI) Cairo Egypt.

3- Res., Agric. Eng. Res. Inst. (AEnRI) Cairo Egypt. 
irrigation practices, better uniformity of water application to the soil and smaller pipe sizes can be selected throughout the system to reduce the initial investment. The required number and size of subunits depends on, field geometry, application rate, irrigation interval, available system capacity, and the desired operating schedule. Keller and Karmeli (1975) stated that a major challenge in system design is to select the optimum size and number of subunits that will achieve economical and efficient operation. Sharaf (1996) developed an interactive model to select the most economical design for trickle irrigation submain unit Efficient micro-irrigation systems must meet peak ET requirements, wet enough portion of the root zone and eliminate runoff. All these criteria affect the initial design and are affected by water availability and quality, energy operational costs, and initial component costs.

Raju and Kumar (2004) applied Genetic Algorithms for irrigation planning. The method used to evolve efficient cropping pattern for maximization benefits for irrigation in India. Their results compared with linear programming solution and found to be reasonably close.

Dandy et al. (1993) outlined the following main optimization techniques which have been applied to water distribution networks as, Partial enumeration (Loubser and Gessler 1990), nonlinear programming (EIBahrawy and Smith (1985)), linear programming (Quindry et at. (1981)) and Genetic algorithms (Hassanli and Dandy (1995)).

A few studies have been reported on the optimization of pressurized irrigation systems considering the field geometry and subunit sizes. Oron and Karmeli (1979) applied the combined Generalized Gradient Pressure (GGP) and Branch \& Bound (B\&B) procedures to an irrigation system to find the optimum values for the number of laterals on a manifold, number of sprinklers on laterals, diameters of manifold and laterals, and the discharges of laterals and sprinklers. Their analysis was limited to minimizing the capital cost for a fixed layout of a sprinkler irrigation system.

Oron and Walker (1981) presented an optimization model for sprinkler irrigation systems. Their model was based on the work of Oron and Karmeli (1979), but extended to various field sizes with various dimensions. The main aims of this work were to compute the number of subunits in both directions of the field, the optimum size of subunits, and 
the associated diameter of the system components. The system cost, which consists of capital and operating costs, was examined as a function of field geometry, consumptive use and pressure head at the water source. They showed that the optimum division of the field into subunits is greatly affected by the field geometry. It depends not only on the area of the field, but also on its width/length ratio and most economical size of the subunit is the square type.

Oron (1982) suggested that fields to be irrigated with permanent pressurized systems should be divided into subunits. The subunit array permits one to irrigate part of the field at a time, achieve a more uniform emitter discharge, increase flexibility in irrigation practices, select smaller pipe sizes throughout the system, and allow one to use an increasing number of emitters per plant during the growing stages of orchards. Holzapfel $\boldsymbol{e t}$ al. 1990 found small cost differences among subunit sizes for a specific field size.

Dandy and Hassanli (1996), proposed a nonlinear model for optimum design and operation of drip irrigation system on flat terrain. Their optimization model procedure involves complete enumeration approach, which minimizes the sum of the capital cost of the system and the present value of operating cost. In the model, the field was divided to subunits with an assumed layout and configuration of piping system.

Water flow in an irrigation distribution network is a nonlinear process; Geohring (1976). Friction head losses determined by Darcy-Weisbach formula vary nonlinearly with changes in discharge and/or pipe diameter. Many existing models are restricted to linear problems in which the optimization of a linear objective function is subject to linear constraints in determining optimal distribution networks, utilized linear programming theory. The nonlinearity of the water flow was linearized by prior assumption of network configuration and by assuming that the discharge and pressure head were known at all points within the network except the source. Since the exact network configuration and pressure distribution are not known in the problem of this study, this approach could not be applied.

Saad and Marino (2002) developed a linear optimization model to design micro irrigation system with tapered downhill lines, minimizing 
the annual cost of the hydraulic network and maximizing the uniformity to subunit. Their model proved to be efficient in designing irrigation system in terms of emission uniformity.

Morimorto et. al., (2007) investigated an optimization water scheduling that improve the quality of Satsuma mandarins using neural networks and Genetic Algorithms. The dynamic changes of sugar and citric content were identified using neural network. An optimal water scheduling was to maximize the sugar contents. Their approach was successful to faithful their objective.

The purpose of this study is to develop an optimization model for design, planning and management of micro irrigation system. The model maintains efficient operation of the system and minimize the total investments cost of the distribution network.

\section{OPTIMIZATION PROBLEM DEVELOPMENT}

An optimum irrigation system must not only be capable of supplying maximum water requirement of a crop, but also supplying these requirements in amounts that reduce plant stress without exceeding infiltration rates or saturating the root zone. These requirements mean that water must be distributed uniformly over the entire irrigated area. Operating policies must be reasonable so that initial investments are minimal.

Approximately 70 to 80 percent of trickle irrigation system cost is attributable to the distribution network components (Dandy and Hassanli, 1996). Therefore, minimization of their costs becomes an important step. Since the number of components and pipe lengths is generally fixed for a given row spacing and field size, it is necessary to select the size and number of subunits which minimize the initial investment cost of the distribution network. Consequently, the optimization problem is to define the costs of all distribution network components and formulate them along with annual operation cost into an objective function. The problem constrained by relationships that insure proper operation of the system of distributing enough and uniform water to meet ET requirements efficiently as described by soil, water, and plant interrelationships.

Current prices for each element were used to determine a continuous 
function of the cost. The components are assumed to be; hydraulically compatible within the distribution network; easily assembled to each other and the expected life of all components is nearly the same. The cost function of pipes and tees were limited to power function. The correlation coefficients generated by the regression analysis varied from 0.94 to 1.0 indicating that satisfactory functions were developed. The prices of pipes and tees are related to the diameter and type of material. For polyethylene (PE) and polyvinyl chloride pipes (PVC), the costs of unit length (m) are:

$$
\begin{aligned}
& C P_{P E}=n 1 D_{1}{ }^{m 1} \\
& C P_{P V C}=n 2 D_{2}{ }^{m 2}
\end{aligned}
$$

Where:

$C P_{P E}=$ cost in L.E. per unit length (m) of polyethylene (PE) pipe.

$C P_{P V C}=$ cost in L.E. per unit length $(\mathrm{m})$ of polyvinyl chloride (PVC) pipe.

$D_{1} \quad$ = inside diameter of lateral or riser pipes, $(\mathrm{mm})$.

$D_{2} \quad$ = inside diameter of manifold, auxiliary, submain and main pipes, (mm)

$n 1, m 1=$ constants for PE pipe cost function

$n 2, m 2=$ constants for PVC pipe cost function

The cost of tees as a function of diameter and type of material are:

$$
\begin{aligned}
& C T_{P E}=n 3 D_{1}{ }^{m 3} \\
& C T_{P V C}=n 4 D_{2}{ }^{m 4}
\end{aligned}
$$

Where:

$C T_{P E} \quad=$ cost in L.E. per unit of polyethylene (PE) tee.

$C T_{P V C}=$ cost in L.E. per unit of polyvinyl chloride (PVC) tee.

$D_{1} \quad=$ inside diameter of polyethylene tee, $(\mathrm{mm})$.

$\mathrm{D}_{2} \quad=$ inside diameter of polyvinyl chloride tee, $(\mathrm{mm})$.

$n 3, m 3=$ constants for $\mathrm{PE}$ tee cost function

$n 4, m 4=$ constants for PVC tee cost function

The cost of control head including filters, flow meters, pressure gages, valves and injection pump as a function of discharge was estimated according to Holzapfel $\boldsymbol{e t}$ al. (1990), by the following:

$$
C_{C H}=C 1\left[k H^{x} * n e * n l * 2 N s x * S\right]-C 2
$$

Where:

$C_{C H}=$ cost in L.E. of the control head.

$k H^{x}=$ emitter flow rate $\mathrm{m}^{3} / \mathrm{h}$ as a function of $\mathrm{H}$, operating pressure and $\mathrm{x}, \mathrm{k}$ $n e \quad=$ No. of emitters along the lateral, including both sides of the manifold 
$n l \quad=$ No. of laterals along both sides of the manifold.

$N s x=$ No. of submains, each serving two subunits parallel to the main line

$S \quad=$ No. of sets working simultaneously.

$C 1, C 2=$ Constants of control head cost function

The cost of pumping system, as a function of power required to operate the system, was estimated by:

$$
C_{P}=C 3\left[\frac{\left(k H^{x} \cdot n e \cdot n l \cdot 2 N s x \cdot S\right) \cdot T D H}{270 . P_{E}}\right]
$$

Where:

$C_{p}=$ cost of pumping station in L.E.

$T D H=$ total dynamic head, m (summation of operating pressure , friction losses, elevation differences and pump suction left)

$P_{E} \quad=$ pumping efficiency including pump and motor (decimal).

C3 = Constant of pumping cost function

Cost of energy is a function of the pump power and operating time during the irrigation season assuming the source of power is electricity:

$$
C_{E}=0.746\left[\frac{\left(k H^{x} \cdot n e \cdot n l .2 N s x \cdot S\right) . T D H}{270 \cdot P_{E}}\right] \cdot \frac{N s y}{S} \cdot L I S . C_{K W H} \cdot T_{r}
$$

Where:

$C_{E}=$ cost of energy L.E.

$L I S=$ No. of irrigation days per season or growing season / irrigation interval.

Nsy = System total No. of sets or No. of subunit parallel to the submain line.

$N s y / S=$ No. of shifts

$C_{K W H}=$ price of kilowatt hour

$T_{r} \quad=$ maximum irrigation hours per shift per day (h/day)

\section{SYSTEM HYDRAULIC LOSSES}

Darcy-Weisbach formula was applied to determine the friction head loss within the piping system, as well as the Blassius equation:

$$
H f(i)=79844.75 . L(i) \cdot Q(i)^{1.75} D(i)^{-4.75} F(i)
$$

Where:

$i \quad=$ subscript the pipe

$H f \quad=$ friction loss along the pipe, (m)

$F \quad=$ reduction factor of the pipe as a function of outlets.

$L \quad=$ pipe length $(\mathrm{m})$

$Q \quad=$ pipe discharge $\left(\mathrm{m}^{3} / \mathrm{h}\right)$ 
$D \quad=$ pipe diameter $(\mathrm{mm})$

Definitions of system piping $(i)$, system length $(L)$, discharge $(Q)$, and number of outlets (no) are given in Table (1).

Table (1): Definitions of system piping components and variables

\begin{tabular}{|l|c|c|c|}
\hline \multicolumn{1}{|c|}{ Pipe (i) } & $\mathrm{L},(\mathrm{m})$ & $\mathrm{Q},\left(\mathrm{m}^{3} / \mathrm{h}\right)$ & Outlet No. no \\
\hline Lateral & $0.5(n e-1) . s e$ & $0.5 n e \cdot k H^{x}$ & INT. $(0.5 n e)$ \\
\hline Manifold & $0.5(n l-1) . s l$ & $0.5(n l \cdot n e) \cdot k H^{x}$ & INT. $(0.5 \mathrm{nl})$ \\
\hline Riser & 0.6 & $n e \cdot k H^{x}$ & - \\
\hline Auxiliary & $0.5(n e . s e)$ & $(n l \cdot n e) \cdot k H^{x}$ & - \\
\hline Submain & $L y-0.5(n l . s l)$ & $2 . S .(n l . n e) \cdot k H^{x}$ & $2 . S$ \\
\hline Main & $L x-(n e . s e)$ & $2 . S . N s x .(n l . n e) \cdot k H^{x}$ & $N s x$ \\
\hline
\end{tabular}

Where:

$L x \quad=$ field length in $\mathrm{x}$ direction, $(\mathrm{m})$

Ly = field length in y direction, $(\mathrm{m})$

se $\quad=$ spacing between emitters $(\mathrm{m})$

$s l \quad=$ spacing between laterals $(\mathrm{m})$

INT = integer number

The pipe outlets reduction factor for the Darcy Weisbach equation was estimated by the following equation:

$$
F(i)=0.33+\frac{1}{2 n o}+\frac{1}{6 n e^{2}}
$$

Minor loss due to emitter connection barb on lateral was estimated by additional length method according to SCS, 1984 by:

$$
f_{e}=1+\frac{18.91}{s e \cdot D l^{1.87}}
$$

Then lateral length (L) changed by (L. $\left.\frac{s e+f e}{s e}\right)$ where $D$ is lateral diameter, (mm).

Tee head loss due to connecting the network pipes was estimated according to Keller and Bliesner, (1990) by:

$$
H f_{T}=K_{T} \frac{V^{2}}{2 g} \quad \text { or } \quad 6375.5 K_{T} \cdot Q_{T}{ }^{2} \cdot D_{T}{ }^{-4}
$$

Where:

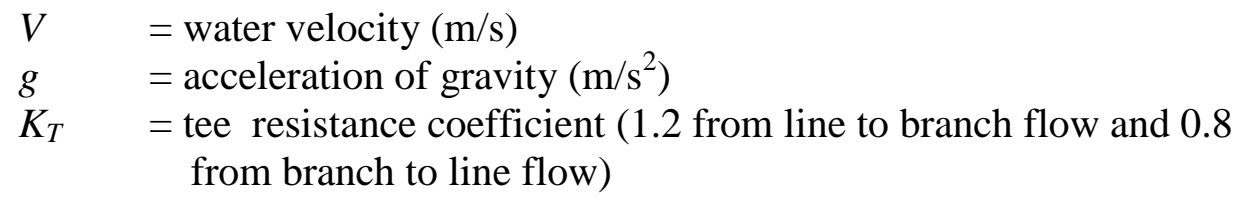


$D_{T} \quad=$ diameter of the tee, $(\mathrm{mm})$

$Q_{T} \quad=$ discharge across the tee $\left(\mathrm{m}^{3} / \mathrm{h}\right)$

In large areas where the field is divided into subunit it is essential to use pressure regulator to assure greater uniformity in water application. Friction loss on it is a function of diameter and discharge. Friction loss at pressure regulator $\left(H F_{P R}\right)$ was approximated by an empirical equation according to Geohrin, (1976) by the following, assuming an average diameter $40 \mathrm{~mm}$ of the auxiliary:

$$
H f_{P R}=0.01336\left(k H^{x} n e . n l\right)^{2}+0.66795\left(k H^{x} n e . n l\right)+1.56941
$$

Head loss at control head $\left(H f_{C H}\right)$, including filter, counter and valves is a function of discharge, and approximated according to Holzapfel $\boldsymbol{e t}$ al. 1990 by:

$$
H f_{C H}=.02\left(2 . S . N s x \cdot(n l . n e) \cdot k H^{x}\right)^{1.474}
$$

\section{MODELING OF THE FIELD GEOMETRY}

The problem of optimizing subunit size and the corresponding piping, fittings, and accessories involves a mixture of integer variables describing the subunit and continuous variables describing the hydraulics and costs. A rectangular or square area will be the assumed field geometry as this is the most common shape of agricultural fields. Variables of the field geometry define integer parameters. A summary of these variables and various constants is illustrated in Fig. (1) and (2). The field geometry in Fig. (2) includes three submain lines $(N s x=3)$, three subunit parallel to the submain line $(N s y=3)$ in Y direction and three sets $(S=3)$ each have 6 subunits.

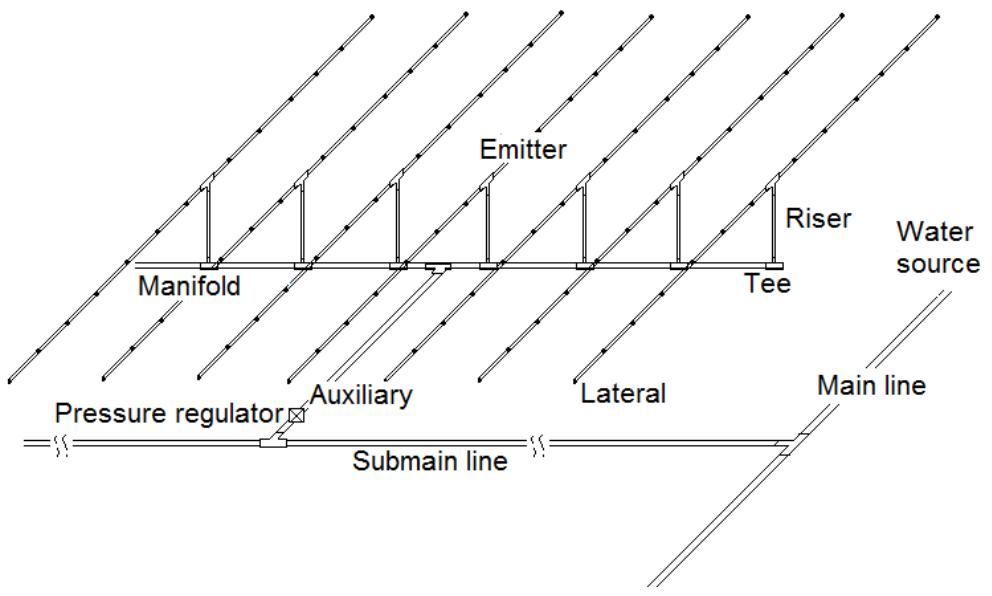

Fig. (1) Schematic diagram of subunit components. 


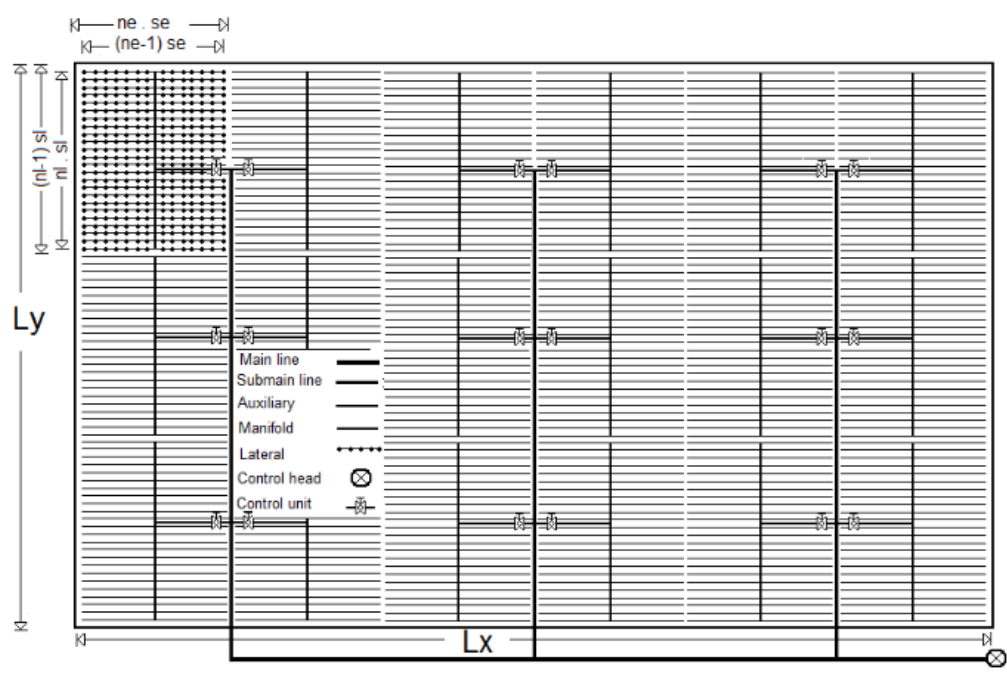

Fig. (2) Field geometry of multiple- subunit trickle irrigation system and parameters description.

The integer variables are $n e, n l, N s x$ and $N s y$ and the constants are $L x, L y$, se and $s l$. The number and/or length of all the field components in the distribution network can be expressed with the above variables and constants as given in Table (2).

Table (2): Field components as a function of constants and variables

\begin{tabular}{|c|c|}
\hline Total No of emitter on the system TNE & $L x * L y\left[\frac{1}{s e * s l}\right]$ \\
\hline Total lateral lengths on the system TLL & $L x * L y\left[\frac{n e-1}{s l * n e}\right]$ \\
\hline Total length of riser (hr) on the system TRL & $L x * L y\left[\frac{h r}{n e * s e * s l)}\right]$ \\
\hline Total length of Manifolds pipes TML & $L x * L y\left[\frac{n l-1}{n e * s e * n l}\right]$ \\
\hline Auxiliary pipe lengths TAL & $L x * L y\left[\frac{0.5}{n l * s l}\right]$ \\
\hline Submain total length TSUL & $N s x\left[L y-\frac{n l * s l}{2}\right]$ \\
\hline Main line total length & $L x-(n e * s e)$ \\
\hline Total No. of end plugs for laterals & $(2 * n l) * \frac{L x * L y}{(n e * s e) *(n l * s l)}$ \\
\hline Tees connecting manifold to auxiliary TMA & $\frac{L x * L y}{(n e * s e) *(n l * s l)}$ \\
\hline $\begin{array}{l}\text { Tees connecting riser to manifold } \text { TRM } \\
\text { Tees connecting lateral to riser }\end{array}$ & $(n l) * \frac{L x * L y}{(n e * s e) *(n l * s l)}$ \\
\hline Tees connecting auxiliary to submain TAS & $\frac{L x * L y}{(n e * s e) *(n l * s l)}$ \\
\hline Tees connecting submain to main TSM & $N s x$ \\
\hline \begin{tabular}{|l|l|} 
Total No. of subunit on the system Ns \\
Total No. of subunit valve TNV \\
Total No. of subunit pressure regulator & TNP \\
\end{tabular} & $\frac{L x * L y}{(n e * s e) *(n l * s l)}$ \\
\hline
\end{tabular}




\section{THE OBJECTIVE FUNCTION}

The objective is to minimize the total cost of the distribution network components plus the annual operating costs. The annual operating costs are included because they are interrelated with the selection of optimum subunit size and number, and thereby, the size and number of the components. Furthermore, operating costs are directly related to the cost of energy (assumed electrical). The mathematical form of the objective function is:

minimize $\quad X_{O}=\left\{\sum_{i=1}^{i=n} C(i) \cdot Y(i)\right\}+C_{O P}$

Where:

$X_{O} \quad=$ total cost of the micro- irrigation system, (L.E.)

$C(i)=$ cost function of the $\mathrm{i}^{\text {th }}$ component in the network, (L.E.).

$n \quad=$ number of different components in the distribution network

$Y \quad=$ total length of pipe $(\mathrm{m})$ or integer number of components.

$C_{O P}=$ annual operating energy cost as function of discharge and head,(L.E.)

\section{Subject to:}

1 - The hydraulic constraint from the distal emitter to the source:

$$
\frac{H e \pm \Delta E+\sum_{i}^{n} H f(i)}{H s} \leq 1
$$

Where:

$\mathrm{He} \quad=$ emitter average pressure head $(\mathrm{m})$

$i \quad=$ subscript $i^{\text {th }}$ component in the distribution system.

$H s \quad=$ pressure head at the source (pump)

$n=$ No. of component on the system; lateral riser, manifold, auxiliary, submain, main, tee connecting pipes, pressure regulator and control head.

$\Delta E \quad=$ elevation difference between the highest outlet point and pump level

2- The hydraulic constraint to achieve acceptable emission uniformity on the subunit:

An acceptable value of emission uniformity can be obtained by limiting the variation of pressure of the emitter within the subunit that include 
lateral and tee connecting riser to lateral, riser and tee connecting manifold to riser, auxiliary and tee connecting auxiliary to manifold. Emission uniformity according to Keller and Karmeli (1975) was defined as:

$$
E U=\left[1-1.27 \frac{v}{\sqrt{n p}}\right] \frac{q_{\text {min }}}{q_{\text {ave }}}
$$

Where:

$E U \quad=$ emission uniformity

$v \quad=$ emitter coefficient of manufacturing variation

$n p \quad=$ No. of emitter per plant

$q_{\min }=$ minimum emitter flow rate $\left(\mathrm{m}^{3} / \mathrm{h}\right)$

$q_{\text {ave }}=$ average emitter flow rate $\left(\mathrm{m}^{3} / \mathrm{h}\right)$

The relationship between emitter type and pressure could be written as:

$$
\frac{H_{\text {min }}}{H_{\text {ave }}}=\left[\frac{q_{\text {min }}}{q_{\text {ave }}}\right]^{1 / x} \text { or } H_{\text {min }}=H_{\text {ave }}\left[\frac{E U}{1-1.27 \frac{V}{\sqrt{n p}}}\right]^{1 / x}
$$

Consider the $H_{\text {ave }}$ is the emitter nominal operating pressure $H_{n}$, therefore the $H_{\max }$ and $H_{\min }$ could be changed to:

$$
H_{\text {max }}=2 H_{n}-H_{\text {min }} \text { and } H_{\text {min }}=H_{n}\left[\frac{E U}{1-1.27 \frac{V}{\sqrt{n p}}}\right]^{\frac{1}{x}}
$$

Therefore, the pressure on emitter in the subunit should be bounded to the following constraint:

$$
H_{\min } \leq H_{e} \leq H_{\max }
$$

In addition to, the allowable pressure variation within the subunit should not exceed the difference between $H_{\max }$ and $H_{\min }$ and could be limited to the following constraint:

$$
\sum_{j=1}^{j=m} H f(j) \pm \Delta e \leq H_{\max }-H_{\min }
$$

Where:

$m \quad=$ No. of components within the subunit; lateral, riser, manifold, auxiliary and tees, $\mathrm{j}$ subscript the component

$H f \quad=$ friction loss on component $\mathrm{j}$ 
3- Equality constraints relating the number of subunits in the field as a function of the total area. The number of subunits parallel to the submain is governed by the following constraint as:

$$
N s y=\frac{L y}{n l * s l} \quad \text { or } \quad \frac{N s y * n l * s l}{L y}=1
$$

Where:

Nsy = No. of subunit along the submain in $\mathrm{Y}$ direction

Ly $\quad=$ Field length parallel to the manifold in $\mathrm{Y}$ direction

$n 1 \quad=$ Integer number of laterals along the manifold.

$s l \quad=$ Spacing between two adjacent laterals

The number of subunits parallel to the main line has to be some multiple of two for the field geometry that is specified. For this reason, Nsx, is defined to be the number of submains which can supply two subunits, and the number of subunits actually becomes $2 * N s x$, realizing this fact, this equality constraint becomes:

$$
2 * N s x=\frac{L x}{n e * s e} \quad \text { or } \quad \frac{2 * N s x * n e * s e}{L x}=1
$$

4- Suitability of emitter flow rate to soil type and crop. The rate of application from an emitter is a function of pressure head and should satisfy the percentage of wetted area (wr), leaching requirements (LR) and the crop evapotranspiration during the irrigation cycle and should not exceed the infiltration capacity of the soil. This could be achieved by the following constraints:

$$
\frac{1000 \cdot k H^{x}}{\text { I.wr.se. sl }} \leq 1
$$

Where:

$I=$ soil infiltration rate, $(\mathrm{mm} / \mathrm{h})$

$w r \quad=$ ratio of wetted area (decimal)

$$
\frac{1000 \cdot k H^{X} \cdot T_{r} \cdot E a \cdot(1-L R)}{\text { se } \cdot s l \cdot E T_{o} \cdot k c \cdot K r}=1
$$

Where:

$T_{r} \quad=$ irrigation time per shift per day, (h/day)

$E a \quad=$ irrigation system efficiency (decimal)

$E T_{o} \quad=$ reference evapotranspiration, $(\mathrm{mm} /$ day $)$

$k c \quad=$ crop coefficient

$K r \quad=$ trickle irrigation reduction factor

$L R \quad=$ leaching requirements 
5- Main and submain line diameters selection criteria. The head losses on the submains and main lines were restricted to two constraints. The first was that friction loss in both of them not exceeds $15 \%$ of the emitter average pressure operating head as:

$$
\frac{H f(\mathrm{sub})+H f(m)}{0.15 \mathrm{He}} \leq 1
$$

The second was that the water velocity not exceeds $1.5 \mathrm{~m} / \mathrm{s}$ :

$$
354 \frac{Q}{D} \leq 1.5
$$

Where:

Q = discharge of submain or main lines, $\left(\mathrm{m}^{3} / \mathrm{h}\right)$

$\mathrm{D}=$ diameter of submain or main lines, $(\mathrm{mm})$

6- The irrigated area by the system must cover the total area:

$$
\frac{(s e \cdot n e) \cdot(s l \cdot n l) \cdot(2 \cdot N s x) \cdot N s y}{L x \cdot L y}=1
$$

7- Management aspects required limiting both lateral and manifold lengths to insure uniformity of water application, therefore, it was suggested the following bounds, as shown in Table (3):

Table (3): Constraints limited lateral and manifold in vegetable and Orchard crops

\begin{tabular}{|c|c|c|}
\hline & orchard & Vegetables or closed spacing \\
\hline Lateral & $30 \leq \frac{(n e-1) s e}{2} \leq 75$ & $25 \leq \frac{(n e-1) s e}{2} \leq 50$ \\
\hline Manifold & $30 \leq \frac{(n l-1) s l}{2} \leq 75$ & $25 \leq \frac{(n l-1) s l}{2} \leq 50$ \\
\hline
\end{tabular}

8- The operating policy would not adequately be described without indication of actual operating time of the system. For any given interval, the total irrigation time has to cover the specified operation time within that interval. This constraint takes the form:

$$
T_{r} \leq T_{\max } \quad \text { and } \quad \frac{T_{r} \cdot N s y \cdot}{S \cdot T_{\max } \cdot F} \leq 1
$$

Where:

$T_{r} \quad=$ irrigation time per shift per day (h/day)

$T_{\max }=$ maximum irrigation hours per day (h/day).

$F \quad=$ irrigation interval, (days) 
9- The number of sets that can operate simultaneously is limited by water availability, the constraint to account for this becomes:

$$
\frac{S .2 N s x \cdot n e \cdot n l \cdot K H^{x}}{Q s} \leq 1
$$

Where:

Qs = water discharge available at the source, $\left(\mathrm{m}^{3} / \mathrm{h}\right)$

10- It is logical that the most economical operating policy is to operate one subunit along each submain line that leads to reduce the submain diameter, but sometimes the optimum integer number of the subunit working simultaneously is difficult to be distributed equally on the submain lines to cover the irrigation time over the irrigation interval. To avoid this problem, it was suggested to use an optimum integer number of sets instead of number of subunits working simultaneously. To insure that at least two subunits attached to each submain line working simultaneously. Therefore, the minimum number of sets (S) which could be applied is one containing 2 Nsx subunits and then the number of shifts equals Nsy/S. Then operating policy constraint of number of shifts becomes:

$$
\frac{N s y}{S}=\text { integer }
$$

\section{ALOGRITHM AND METHOD USED}

The optimization model was run using the Microsoft Excel Solver tool that applies the Generalized Reduced Gradient (GRG2) nonlinear optimization code. Integer problems use the simplex method with bounds on the variables, and the branch-and-bound method.

The model is carried out by complete enumeration of all alternatives. The basic inputs are:

- Dimensions of the field, (LX), and (LY).

- The spacing between emitters, (se), and laterals, (sl).

- No of irrigation days per season (LIS), and hours available per day for irrigation $(\mathrm{Tr})$.

- Soil field capacity ( FC \%), welting point (Wp \%), wetted area (Wr $\%)$, root depth $(\mathrm{Rd})$ and depletion ratio $(\mathrm{dr})$. 
- Plant evapotranspiration (ETo), crop coefficient (Kc), reduction factor $(\mathrm{Kr})$ and soil infiltration rate (Ir).

- Emitter constant (x, k), price (Ce), coefficient of flow variation (cv), No of emitter per plant (n) and nominal operating pressure (Ho)

- System application efficiency (Ea) and emission uniformity (EU)

- Source available flow rate (Qs)

- The energy cost (C-kWh)

- The cost functions of the system component.

- Efficiencies for the electric motor ( $\eta \mathrm{m})$ and pump ( $\eta$ )

Assumptions:

In the optimization model, the general configurations of the conveyance piping system within the field (main and submain lines) and within the subunits (lateral, riser, manifold and auxiliary) are fixed. However, the area and the dimensions of the subunits in both $\mathrm{X}$ and $\mathrm{Y}$ direction change in each run, the lengths and size of all pipes change as well. The model was developed for a field with given area and known dimensions for which the water source is located at any one of the four corners. However, the model can be easily applied to any size and dimensions of field.

\section{RESULTS AND DISCUSSION}

The main objective of the study is to identify an optimum design and planning of micro-irrigation system based on multiple subunit system. The model enables an examination of the influence of subunit sizes and shifts on the system total cost and find an optimum solution among various operating conditions. A number of effects were evaluated and discussed among case studies.

Case Study

A numerical example presented as case study to identify the model utility. Assume we need to optimally design and plan a micro irrigation system for a farm of 43.12 Fed. The input data presented in Table(4). The objective function target cell and formulation of constraints showed in solver screen as shown in Fig. (3). The constraints and their values for the case study were presented in Table (5). When solver found solution and all constraints are satisfied, a massage appeared as shown in Fig. (4) 
Table. (4): Constants and input data for the case studies.

\begin{tabular}{|c|c|c||c|c|c||c|c|}
\hline Variable & value & unit & Variable & value & unit & Variable & value \\
\hline $\mathrm{Se}$ & 5 & $\mathrm{~m}$ & $\mathrm{X}$ & 0.5 & - & $\mathrm{n} 1$ & 0.4325 \\
\hline $\mathrm{Sl}$ & 5 & $\mathrm{~m}$ & $\mathrm{Ce}$ & 7 & LE. & $\mathrm{m} 1$ & 1.0970 \\
\hline $\mathrm{LSI}$ & 180 & day & $\mathrm{CV}$ & 0.05 & - & $\mathrm{n} 2$ & 0.0063 \\
\hline $\mathrm{Tr}$ & 20 & $\mathrm{hr}$ & $\mathrm{n}$ & 1 & - & $\mathrm{m} 2$ & 1.6250 \\
\hline $\mathrm{FC}$ & 20 & $\%$ & $\mathrm{Ho}$ & 20 & $\mathrm{~m}$ & $\mathrm{n} 3$ & 0.2010 \\
\hline $\mathrm{WP}$ & 10 & $\%$ & $\mathrm{Ea}$ & 90 & $\%$ & $\mathrm{~m} 3$ & 1.0950 \\
\hline $\mathrm{Wr}$ & 50 & $\%$ & $\mathrm{EU}$ & 90 & $\%$ & $\mathrm{n} 4$ & 0.0120 \\
\hline $\mathrm{Rd}$ & 1 & $\mathrm{~m}$ & $\mathrm{Qs}$ & 1000 & $\mathrm{~m} 3 / \mathrm{hr}$ & $\mathrm{m} 4$ & 1.1960 \\
\hline $\mathrm{dr}$ & 50 & $\%$ & $\mathrm{PE}$ & 60 & $\%$ & $\mathrm{C} 1$ & 345.0 \\
\hline $\mathrm{Ir}$ & 12.4 & $\mathrm{~mm} / \mathrm{hr}$ & $\mathrm{C}-\mathrm{kWh}$ & 0.4 & $\mathrm{LE} . / \mathrm{kwh}$ & $\mathrm{C} 2$ & 275.0 \\
\hline $\mathrm{ETcrop}$ & 8 & $\mathrm{~mm} / \mathrm{day}$ & $\mathrm{C}-\mathrm{EP}$ & 0.5 & LE. & $\mathrm{C} 3$ & 350.0 \\
\hline $\mathrm{K}$ & 0.008 & - & $\mathrm{C}-\mathrm{PR}$ & 100 & - & & \\
\hline
\end{tabular}

Table (5):Results of satisfaction the hydraulic and management constrains

\begin{tabular}{|l|c|l|}
\hline Parameters & Limit & Actual output \\
\hline 1- For total system to find the pressure at source & $\leq 1$ & 1.00000000 \\
\hline 2 - To insure the uniformity at subunit & $\leq 1$ & 1.00000000 \\
\hline 3- Constrain friction loss of main and submain & $\leq 1$ & 1.00000000 \\
\hline 4- Irrigation available time & $\leq 1$ & 0.26762956 \\
\hline 5- Limiting ETcrop & $\leq 1$ & 1.00000000 \\
\hline 6- Operating subunits less than total & $\leq 1$ & 0.01666666 \\
\hline 7- Average pressure higher than Hmin & $\geq 1$ & 1.19959458 \\
\hline 8 - Limiting Run Off & $\leq 1$ & 0.24106502 \\
\hline 9- Limiting water velocity on submain & $\leq 1$ & 1.00000000 \\
\hline 10 - Limiting water velocity on main & $\leq 1$ & 1.00000000 \\
\hline 11-Operating one subunit along each submain & $=1$ & 1.00000000 \\
\hline 12- Limiting No of Shifts & $\geq 1$ & 6.00000000 \\
\hline 13- limiting irrigation frequency & $\leq 1$ & 0.53525910 \\
\hline 14 - average pressure less than Hmax & $\leq 1$ & 1.00000000 \\
\hline 15- limiting No. of subunit parallel to submain & $=1$ & 1.00000000 \\
\hline 16- Limiting No. of subunit parallel to main & $=1$ & 1.00000000 \\
\hline 17- Constrained irrigation area & $=1$ & 1.00000000 \\
\hline 18- Limiting lateral length 1 & $\geq 25$ & 25.0000000 \\
\hline 19- Limiting lateral length 2 & $\leq 80$ & 25.0000000 \\
\hline 20- Limiting manifold length 1 & $\geq 25$ & 25.0000000 \\
\hline 21- Limiting manifold length 2 & $\leq 80$ & 25.0000000 \\
\hline 22- Enough water available at the source & $\geq 1$ & 1.00000000 \\
\hline
\end{tabular}

Typical results of the model for total costs of 43.12 Fed. were illustrated in Table (6). The results indicated that the total area divided into 60 
subunits. The system has 5 submain lines and each set contain 10 subunits and lateral length is $50 \mathrm{~m}$ and the manifold have the same length. The minimum total cost was 2955 LE./Fed. this value was due to operating the system in 6 shifts where 10 subunits operated simultaneously. The other parameters of design, operation and cost analyses are illustrated in Table (6). Material and equipment list shown in Table (7). The configuration and planning of the system according to this design criteria is shown in Fig(5).

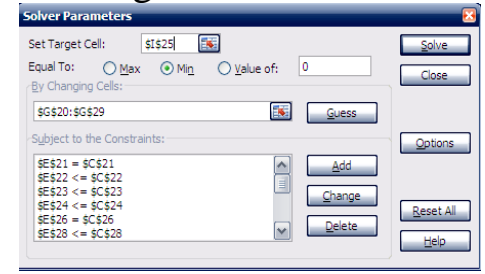

Fig. (3 ) : typical solver screan for options and formulating the consraints

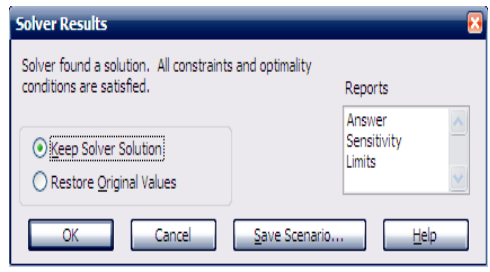

Fig. (4): massage of solver when constraints are satisfied and solver found solution

Table ( 6 ): Results of minimum capital cost for 43.21 Fed. applied six shifts.

\begin{tabular}{|c|c|c|c|}
\hline Area( Fed.) & 43.21428571 & Materials & Cost $\%$ \\
\hline $\mathrm{SX}(\mathrm{m})$ & 550 & Lateral & 12.07444 \\
\hline SY (m) & 330 & Riser & 0.119442 \\
\hline DX (m) & 5 & Manifold & 2.000142 \\
\hline DY (m) & 5 & Auxiliary & 3.137806 \\
\hline NS & 60 & Submain & 5.610544 \\
\hline Nsx & 5 & Main & 6.360669 \\
\hline Nsy & 6 & emitters & 39.79164 \\
\hline $\mathrm{NX}$ & 11 & Total & 69.09468 \\
\hline NY & 11 & & \\
\hline No. of shifts & 6 & Accessories. & 5.708934 \\
\hline Irr. Time hr & 5.352591324 & C. head & 4.019887 \\
\hline $\mathrm{DL}(\mathrm{mm})$ & 13.54650287 & Pumping & 4.146466 \\
\hline DR $(\mathrm{mm})$ & 16.96886285 & Energy & 17.03003 \\
\hline $\mathrm{DM}(\mathrm{mm}$ & 22.27792837 & \multirow{2}{*}{ Total } & \multirow{2}{*}{100} \\
\hline DA $(\mathrm{mm})$ & 46.03139626 & & \\
\hline $\mathrm{DSU}(\mathrm{mm})$ & 59.28177668 & T. cost ( L.E.) & 127715.3 \\
\hline DMI (mm) & 131.4850527 & Cost/Fed. (L.E) & 2955.395 \\
\hline $\mathrm{He} \quad(\mathrm{m})$ & 21.81483064 & & \\
\hline H source $(\mathrm{m})$ & 43.21428571 & & \\
\hline Emitter $\left(\mathrm{m}^{3} / \mathrm{h}\right)$ & 0.037365079 & & \\
\hline System Q & 45.21174611 & $\mathrm{~T}$ friction loss $(\mathrm{m})$ & 12.39982 \\
\hline head at pump & 54.21465555 & Subunit FL (m) & 3.629662 \\
\hline Pump( HP) & 15.13048915 & FL of $\mathrm{M}+\mathrm{S}(\mathrm{m})$ & 3.357103 \\
\hline Pump (KW) & 11.28734491 & subunit size $\left(\mathrm{m}^{2}\right)$ & 3025 \\
\hline
\end{tabular}




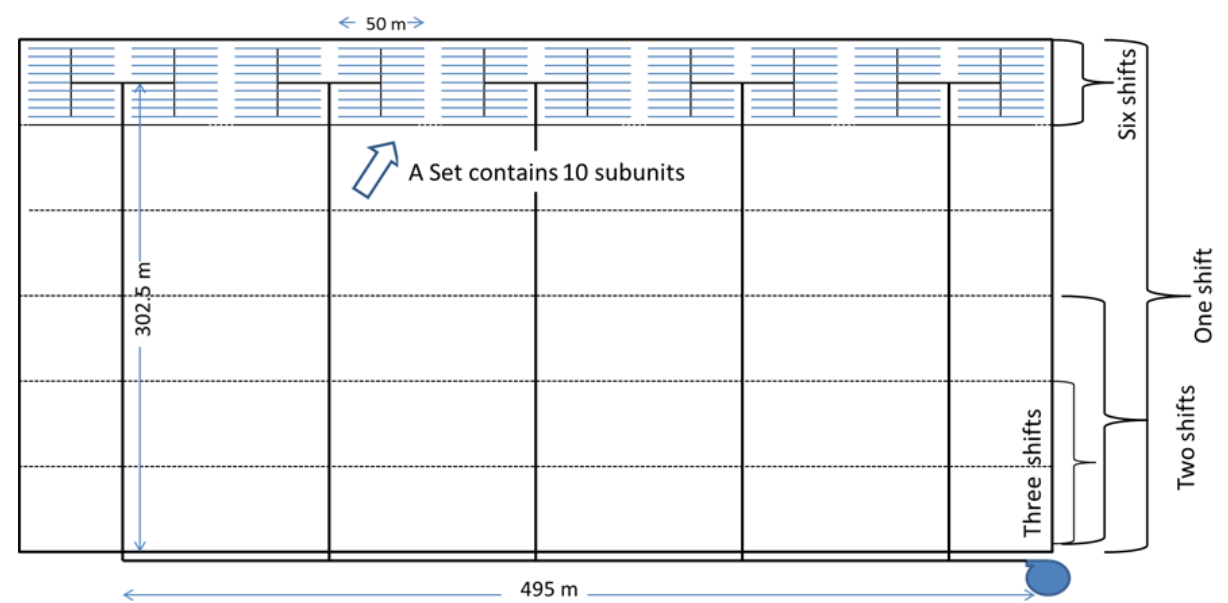

Fig.(5): schematic diagram of 43.21 Fed. and possible options of operating the system in one, two, three or four shifts that get the minimum cost.

Table (7): Result of material and equipment for list for 43.21 Fed.

\begin{tabular}{|c|c|c|}
\hline Variable & Quantity & Unit \\
\hline Total No of emitter on the system & 7260 & piece \\
\hline Total lateral lengths on the system & 33000 & $\mathrm{~m}$ \\
\hline End plugs for laterals & 1320 & piece \\
\hline Total Tees connecting lateral to riser & 660 & piece \\
\hline Total length of riser on the system & 396 & $\mathrm{~m}$ \\
\hline Tees connecting riser to manifold TRM & 660 & piece \\
\hline Total length of Manifolds pipes & 3000 & $\mathrm{~m}$ \\
\hline Tees connecting manifold to auxiliary TMA & 60 & piece \\
\hline Auxiliary pipe lengths TAL & 1650 & $\mathrm{~m}$ \\
\hline Submain total length TSUL & 1512.5 & $\mathrm{~m}$ \\
\hline Tees connecting auxiliary to submain TAS & 60 & piece \\
\hline Main line total length & 495 & $\mathrm{~m}$ \\
\hline Tees connecting submain to main TSM or NXM & 5 & piece \\
\hline Total No of subunit on the system & 60 & No. \\
\hline Total No of subunit valve & 60 & No. \\
\hline Total No of subunit pressure regulator TNP & 60 & No. \\
\hline
\end{tabular}

\section{ANALYSIS OF THE MODEL}

The micro-irrigation optimization model was analyzed for runs using data given in Table (4). This represents irrigation of Orchard crop (plant spacing $5 \mathrm{~m}$ x $5 \mathrm{~m}$ ) field areas as 15.32 Fed. (390 m x165 m), 22.29 Fad. 
(390 m x $240 \mathrm{~m}$ ), 43.21 Fed. (550 m x $330 \mathrm{~m}$ ) and 91.93 Fed. (780 m x $495 \mathrm{~m})$. The results are presented in Table (8). The upper part of the Table (8) shows the configuration and the layout of the system. The lower part of the table shows management options in case of operating the system for minimum capital cost where the numbers of shifts were 9 , $6,4,3$ respectively and the maximum capital costs when the system operates in one shift and the operational variables related to each operation option.

Irrigating a set of subunits instead of irrigating the whole system simultaneously along with decreasing the total capital and operation cost increases the flexibility and the reliability of the system. Applying partial irrigation to the whole land requires mostly higher emitter flow rate and pressure operating head, which may overcome clogging problems and provide greater wetted area. It is also more flexible in relation to sharing irrigation water for specified set of subunits when available water is either provided from different sources or the field belongs to different owners. It was observed that by increasing the number of shifts, the network, pumping, control head, costs are decreased while energy and emitter costs are increased

Effect of total area and number of shifts on total capital cost:

The total capital cost of different areas, 91.93, 43.21, 22.29 and 15.32 Fed. irrigated according to the design planned and management criteria resulted in 2917 LE./Fed ( 9 shifts were applied), 2955 LE./Fed. (6 shifts were applied), 3184 L.E./Fed. (4 shifts were applied) and 3262 L.E./Fed. (3 shifts were applied) respectively. The total capital cost of the previous configurations applying one shift (The whole area is irrigated once in time) showed different results as 6108, 5286, 4817 and 4691 L.E./Fed, respectively. The results indicated in Fig.(6).

In case of applying the system for minimum capital cost, where number of subunit working simultaneously is in one set (higher number of shifts), it is clear that minimum total cost is decreased by different ratios depends on total area, number of shifts and number of subunit per set. The total cost in these cases followed power function as:

$$
X o=3864 \text { area }^{-0.62} \quad R^{2}=0.99
$$

The total cost per unit area $(X o)$ increased by increasing the irrigated total 
area in one shift policy as shown in Fig. (6). The relationship showed also power function as:

Xo $=3085$ area $^{0.48} \quad R^{2}=0.98$

Where:

$$
92 \geq \text { area } \geq 15 \mathrm{Fed}
$$

Another option of management is to decrease the number of shifts (increasing the number of sets operating simultaneously), this leads to decrease the irrigation time but increase the total capital cost per unit area, the results in Table (9) indicated that the use of higher number of irrigation shifts or decreasing the number of sets operate simultaneously is more economic.

The effect of uniformity on total cost

Effect of uniformity on total cost was investigated for the system total area 43.12 Fed., where the system operated in one and six shifts. The results presented in Fig. (7). The trend was exponential. The effect was higher in case of operating the system in one shift where the total cost increased from 5075 to 5500 L.E./Fed to improve the uniformity from 0.8 to 0.9 . The same trend was found in case of operating the system in 6 shifts (minimum capital cost) where the cost increased from 2863 to 2965 L.E./ Fed. to improve the uniformity for the same range.

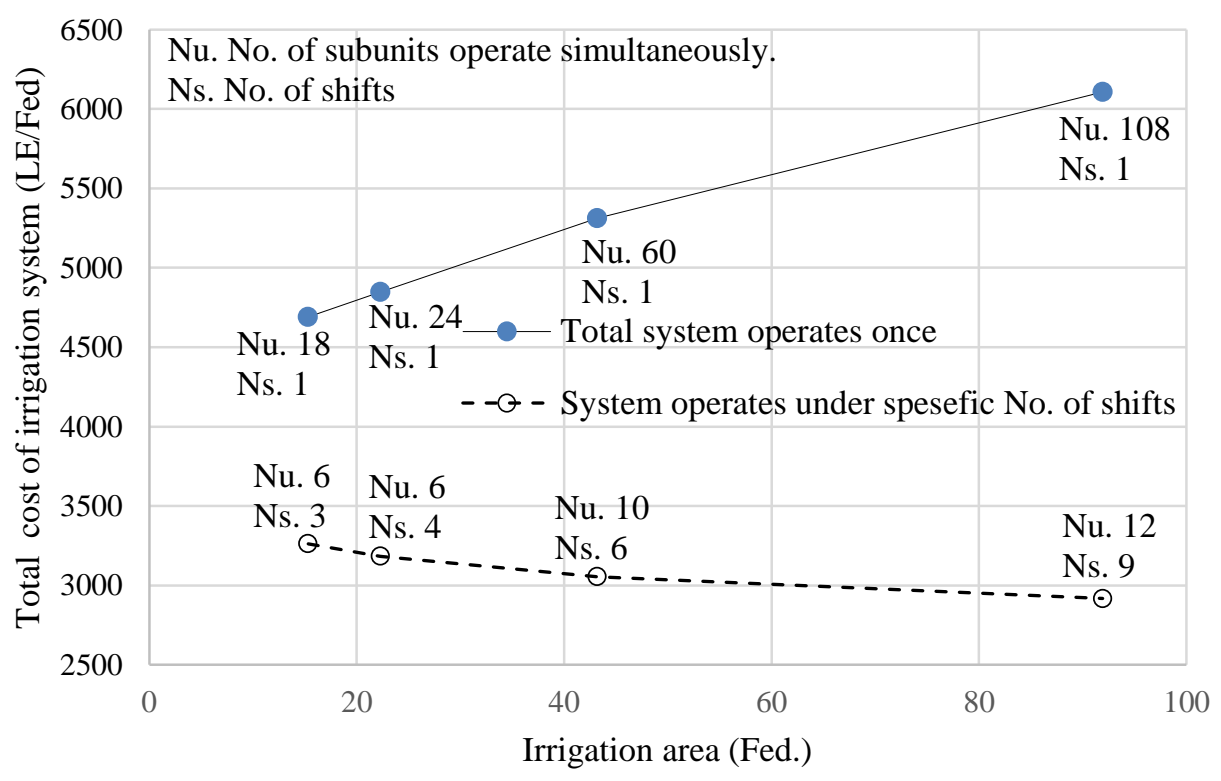

Fig. (6): Effect of total area and No. of shifts on total cost. 
Table (8):Results of design, management and minimizing cost of some micro-irrigation areas.

\begin{tabular}{|c|c|c|c|c|c|c|c|c|}
\hline \multirow{2}{*}{ Variables } & \multicolumn{8}{|c|}{ Total area fed. } \\
\hline & \multicolumn{2}{|l|}{91.93} & \multicolumn{2}{|l|}{43.21} & \multicolumn{2}{|l|}{22.29} & \multicolumn{2}{|l|}{15.32} \\
\hline Length Lx(m) & \multicolumn{2}{|l|}{780} & \multicolumn{2}{|l|}{550} & \multicolumn{2}{|l|}{390} & \multicolumn{2}{|l|}{390} \\
\hline Width Ly (m) & \multicolumn{2}{|l|}{495} & \multicolumn{2}{|l|}{330} & \multicolumn{2}{|l|}{240} & \multicolumn{2}{|l|}{165} \\
\hline No. of submain lines Nsx & \multicolumn{2}{|l|}{6} & \multicolumn{2}{|l|}{5} & \multicolumn{2}{|l|}{3} & \multicolumn{2}{|l|}{3} \\
\hline No. of subunit on Y direction (Nsy) & \multicolumn{2}{|l|}{9} & \multicolumn{2}{|l|}{6} & \multicolumn{2}{|l|}{4} & \multicolumn{2}{|l|}{3} \\
\hline No. of emitters on lateral (ne) & \multicolumn{2}{|l|}{13} & \multicolumn{2}{|l|}{11} & \multicolumn{2}{|l|}{13} & \multicolumn{2}{|l|}{13} \\
\hline No. of laterals on manifold (nl) & \multicolumn{2}{|l|}{11} & \multicolumn{2}{|l|}{11} & \multicolumn{2}{|l|}{12} & \multicolumn{2}{|l|}{11} \\
\hline Total No. of subunits (Ns) & 108 & & 60 & & 24 & & 18 & \\
\hline Lateral length Ll (m) & 60 & & 50 & & 60 & & 60 & \\
\hline Manifold length (Lm) $\mathrm{m}$ & 50 & & 50 & & 55 & & 50 & \\
\hline Auxiliary length $(\mathrm{La}) \mathrm{m}$ & 32.5 & & 27.5 & & 32.5 & & 32.5 & \\
\hline Submain length (Lsub) $\mathrm{m}$ & 467.5 & & 302.5 & & 210 & & 137.5 & \\
\hline Length of main line (Lmain) $\mathrm{m}$ & 715 & & 495 & & 325 & & 325 & \\
\hline No. of Shifts & 1 & 9 & 1 & 6 & 1 & 4 & 1 & 3 \\
\hline Emitter flow rate $(\mathrm{q}) \mathrm{m}^{3} / \mathrm{h}$ & 0.0353 & 0.0374 & .0354 & .0374 & .0355 & .0373 & .0350 & .0367 \\
\hline Average operating pressure head $\mathrm{He}(\mathrm{m})$ & 19.48 & 21.81 & 19.60 & 21.82 & 19.72 & 21.75 & 19.34 & 21.14 \\
\hline Pressure head at pump (Hs) (m) & 48.95 & 35.32 & 34.15 & 34.22 & 31.05 & 33.13 & 29.22 & 32.49 \\
\hline Total dynamic head TDH $(\mathrm{m})$ & 68.94 & 55.32 & 54.15 & 54.22 & 51.05 & 53.13 & 49.22 & 52.49 \\
\hline System water capacity $\left(\mathrm{m}^{3} / \mathrm{h}\right)$ & 545.30 & 64.12 & 257.12 & 45.21 & 133.00 & 34.93 & 90.56 & 31.56 \\
\hline Pump power(KW) & 173.13 & 16.31 & 64.12 & 11.29 & 31.27 & 8.55 & 20.53 & 7.63 \\
\hline Irrigation time (hr/shift) & 5.66 & 5.35 & 5.65 & 5.35 & 5.63 & 5.36 & 5.68 & 5.44 \\
\hline Total Cost/.fed. (L.E). & 6107 & 2913 & 5285 & 2955 & 4817 & 3184 & 4691 & 3262 \\
\hline Cost of Piping $\%$ & 42.12 & 31.59 & 38.0 & 29.30 & 35.37 & 32.16 & 34.21 & 30.29 \\
\hline Cost of Accessories\% & 2.46 & 4.94 & 3.3 & 5.71 & 2.86 & 4.21 & 3.15 & 4.44 \\
\hline Cost of Emitter \% & 19.26 & 40.31 & 22.25 & 39.79 & 24.27 & 36.93 & 25.07 & 36.05 \\
\hline Cost of Pumping \% & 14.47 & 2.85 & 13.17 & 4.15 & 13.58 & 5.65 & 13.40 & 7.16 \\
\hline Cost of control Head \% & 11.21 & 2.73 & 12.97 & 4.02 & 14.15 & 5.56 & 14.44 & 7.12 \\
\hline Cost of Energy \% & 10.68 & 17.58 & 9.51 & 17.03 & 7.78 & 15.49 & 9.74 & 14.94 \\
\hline
\end{tabular}


Table ( 9 ): Total cost related to No. of shifts and No. of subunits operate simultaneously related to the total area.

\begin{tabular}{|c|c|c|c|c|c|c|c|c|c|c|}
\hline \multicolumn{2}{|c}{ Area } & \multicolumn{7}{|c|}{ No. of shifts* } \\
\cline { 2 - 10 } 15.32 & $\begin{array}{c}\text { Cost } \\
\text { LE./Fed. }\end{array}$ & 4691 & - & 3262 & - & - & - & - & - & - \\
\cline { 2 - 10 } & $\begin{array}{c}\text { No. of } \\
\text { subunits* }\end{array}$ & 18 & & 6 & - & - & - & - & - & - \\
\hline \multirow{2}{*}{22.29} & $\begin{array}{c}\text { Cost } \\
\text { LE./Fed. }\end{array}$ & 4847 & 3697 & - & 3184 & - & - & - & - & - \\
\cline { 2 - 11 } & $\begin{array}{c}\text { No. of } \\
\text { subunits* }\end{array}$ & 24 & 12 & - & 6 & - & - & - & - & - \\
\hline \multirow{2}{*}{$\begin{array}{c}\text { Cost } \\
\text { LE./Fed. }\end{array}$} & 5286 & 3910 & 3439 & - & - & 2955 & - & - & - \\
\hline $\begin{array}{c}\text { No. of } \\
\text { subunits* }\end{array}$ & 60 & 30 & 20 & - & - & 10 & - & - & - \\
\hline $\begin{array}{c}\text { Cost } \\
\text { LE./Fed. }\end{array}$ & 6107 & - & 3708 & - & - & - & - & - & 2917 \\
\hline $\begin{array}{c}\text { No. of } \\
\text { subunits* }\end{array}$ & 108 & - & 36 & - & - & - & - & - & 12 \\
\hline
\end{tabular}

* No. of subunit per set is the subunit No. at the higher No. of shifts.

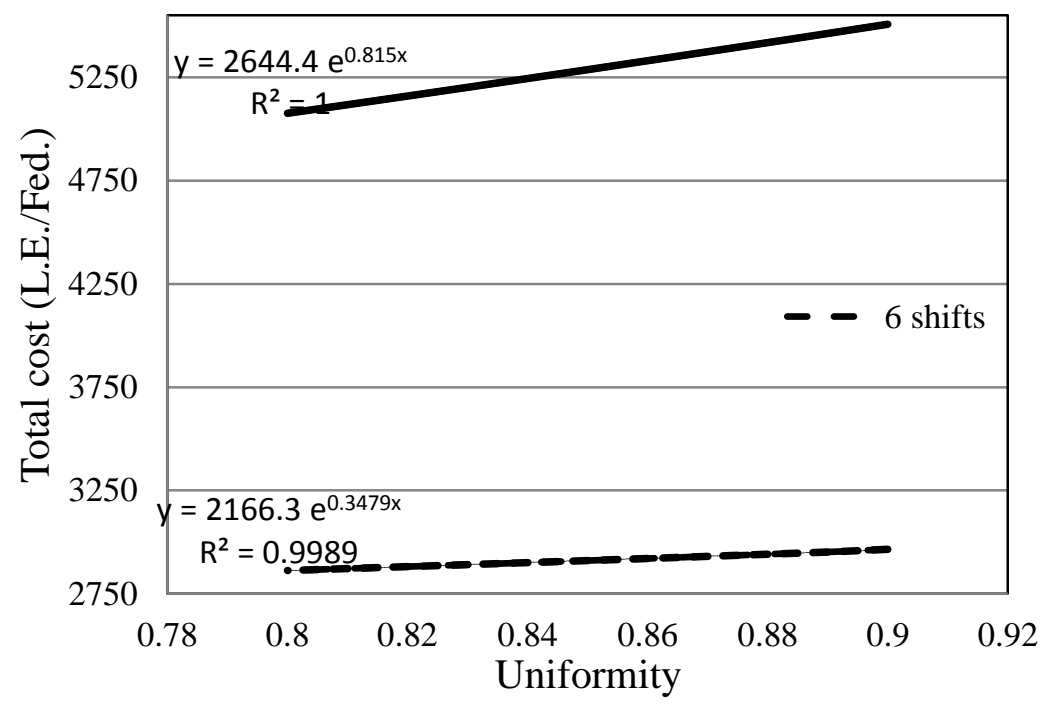

Fig. (7): Effect of uniformity on total cost in case of operating the system for minimum cost (6 shifts) and maximum cost (one shift) 


\section{SUMMARY AND CONCLUSIONS}

An optimization model for micro irrigation system design, planning and cost estimation was developed. The model divided the field into subunits with an assumed land layout and configuration of piping system. The model selects among different layouts, number of shifts, number of sets and number of subunit per set with minimum total cost. The model was developed using the Microsoft Excel Solver tool that applies the Generalized Reduced Gradient (GRG2) nonlinear optimization code. The model can be applied to rectangular field with water source at any of its corners. The model can be applied to various field sizes, crops, soil types, and regions. This can be achieved by specifying the input data such as field dimensions, emitter function, lateral and manifold spacing, crop coefficient, evapotranspiration and irrigation requirements and soil hydraulic properties. When applied a case study the results indicated that minimum cost is decreased by increasing the total area to be irrigated when just one set of subunit operates simultaneously. Meanwhile the total costs increased by increasing the total area in case of irrigate the whole area once in time (one shift). The rate of increase depends on number of shifts, number of sets and number of subunit per set operate simultaneously. The total costs were affected the emission uniformity. Results indicated that the total cost increased at higher uniformity. This effect increased by decreasing the number of shifts.

\section{REFERENCES}

Dandy, G. C., and A. M. Hassanli (1996). Optimum design and operation of multiple subunit drip irrigation systems. J. of irrig. And drain. Eng. ASCE, 122 (5).265-275.

Dandy G. C., Simpson, A. R., and Murphy, L. J. (1993). A review of pipe network optimization techniques. Proc., Watercomp 93, $2^{\text {nd }}$ Australian Conf. on Tech. Computing in the water industry, Instn . of Engrs., Canberra, Australia.

El-Bahrawy, A. N., and Smith, A. A. (1985). Application of MINOUS to water collection and distribution networks. Civ. Eng. Sys., 2(1).

Goehring, L. D. (1976). Optimization of trickle irrigation system design. 
Unpublished M.Sc. Thesis, Colorado State U., Fort Collins, Colo..

Hassanli , A. M., and Dandy, G. C. (1995). Least cost layout model for pressure irrigation system using genetic algorithms. Proc., Regional Conf. on water resource Management (WRM` 95 ). Isfahan Uni. Iran.

Holzapfel, E. A., Marino, M. A., and Valenzuela, A. (1990). Drip irrigation nonlinear optimization model. J. irrig. and Drain. Eng. ASCE, 116(4), 479-496.

Keller, J. and Karmeli, D. (1975). Trickle irrigation design. Rainbird Sprinkler Manufacturing Crop., Glendora, Calif..

Keller, J. and R. D. Blusner, (1990). Sprinkler and Trickle irrigation. An avi. Book, Champman \& Hall N.Y. 629 PP.

Loubser, B. F., and Gessler, J. (1990). Computer aided optimization of water distribution networks. The Civ. Eng. in south Africa.

Morimoto, T, Y. Ouchi, M. Shimizu and M. S. Balch (2007). Dynamic optimization of watering Satsuma mandarin using neural networks and genetic algorithms. Ag. Water Management, 93, 1-10.

Oron , G., and Karmeli, D. (1979). Procedure for the economical evaluation of water networks parameters. Water Resource Bull., 15(4), $1050-1059$.

Oron, G. (1982). Technical and economical consideration in the design of permanent conduit irrigation systems: A case study. Agric. Water management, 5(1), 15-27.

Oron, G.,and Walker, W. (1981). Optimal design and operation of permanent irrigation system. Water Resou. Res., 17 (1), 11-17.

Quindry, G. E., Brill, E. D., and Liebman, J. C. (1981). Optimization of looped water distribution systems. J. irrig. and Drain. Eng . ASCE, 107(4), 665-679.

Raju, K. Spinivasa and D. Nagesh Kumar (2004). Irrigation planning using Genetic Algorithm, Water Resources Management. 18: 163 176. 
Saad and Marino (2002). Optimal design of micro irrigation system in sloping lands. J. irrig. and Drain. Eng ASCE, 128, 116 -124.

Sharaf, G. A. (1996). Optimal design of trickle irrigation submain unit. Misr J. AG. Eng., 13 93): 501-515

Soil conservation service (SCS), (1984). Trickle irrigation, US dept. of Agric. National Eng. Handbook. Ch(15), Sec(15).

\section{الملخص العربي}

\section{نمذجة التصميم والإدارة الأمثلين لنظم الري المصغرة جمال شرف' ، عزة حسن" ، هاشم محمود"}

الهذف من هذا البحث هو خفض التكاليف الكلية لوحدات الري المصغر من خلال نطوير نموذج للتخطيط والتصميم والإدارة الأمنلين وتقليل التكاليف، وقد تم استخدام بحوث العمليات كتطبيق

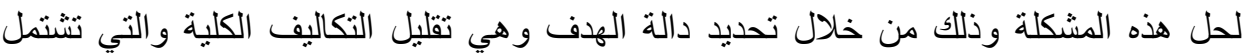
تكاليف المعدات والأجهزة وتكاليف التتغيل السنوية نتيجة لمجمو عة من القيود التي تتظم عمليات التخطيط و التصميم و التشغيل. وقد تم الاستعانة بوسيلة حل نماذج بحوث التهو العمليات الغير خطية

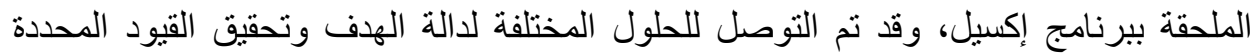

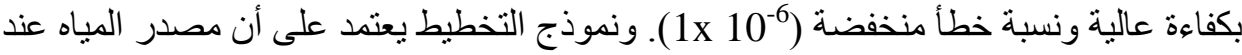

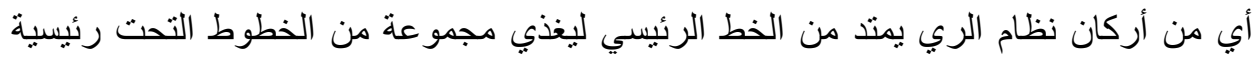

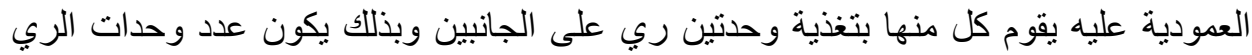

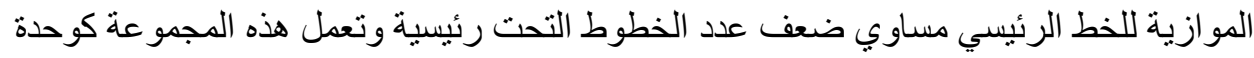

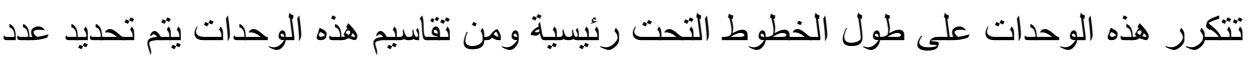

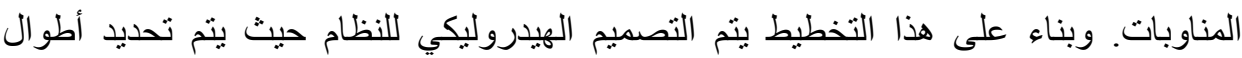

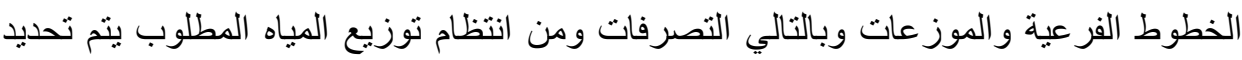

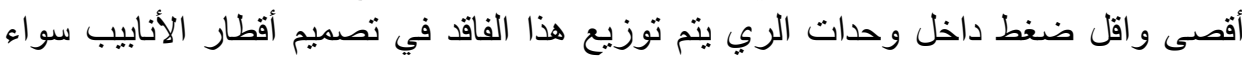

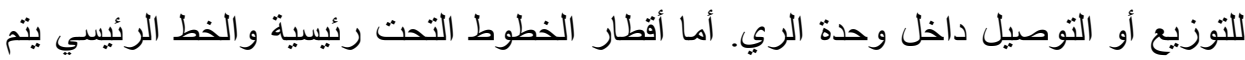

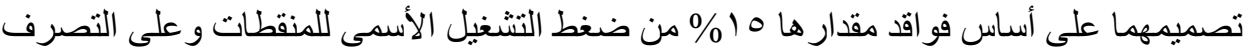

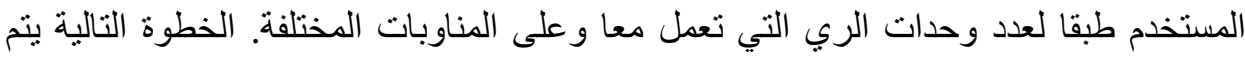

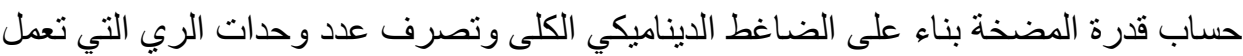


وبعد ذللك يتم حساب التكاليف مع التقيد بالثروط التي تحقق دالة الهدف في حساب اقل التكاليف

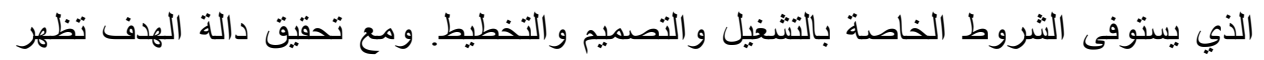

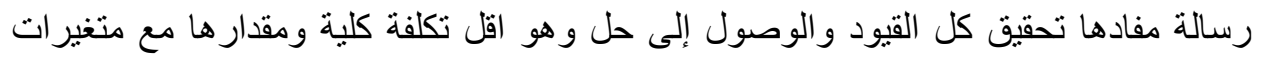

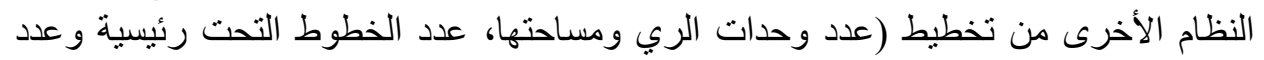

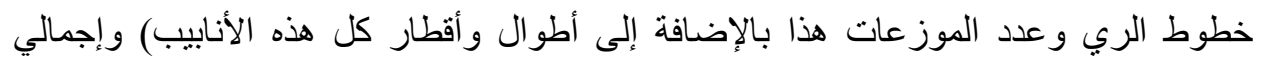

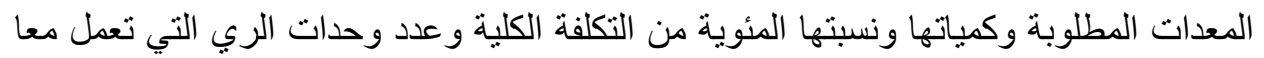

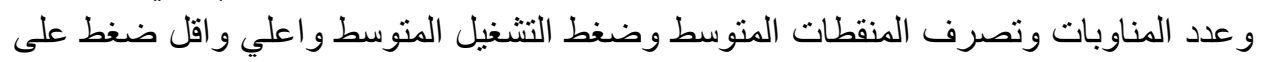

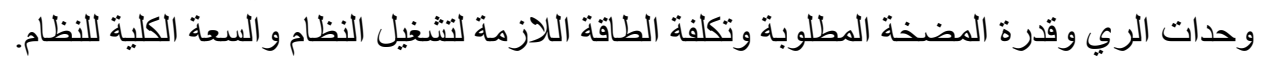

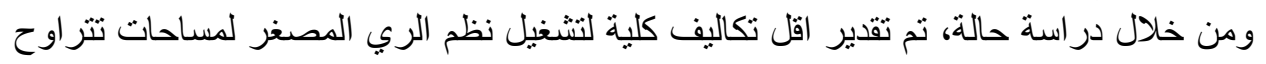

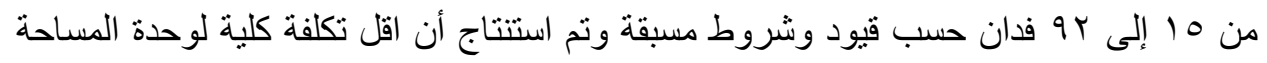

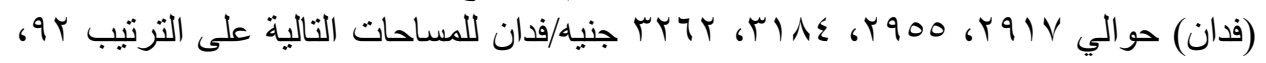

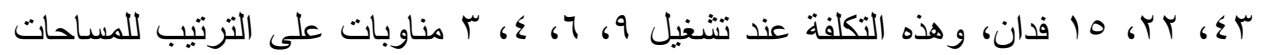

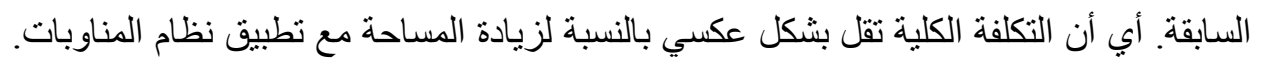

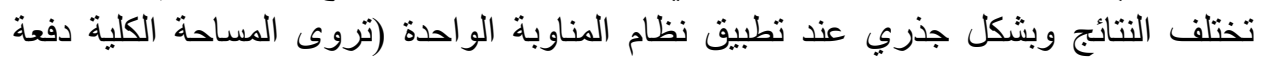

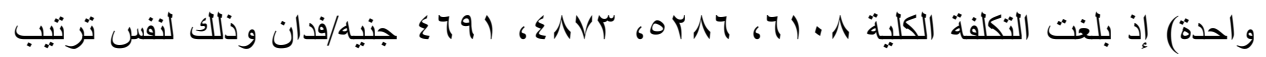

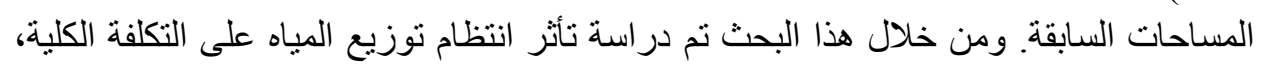

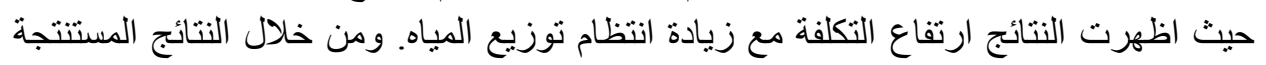

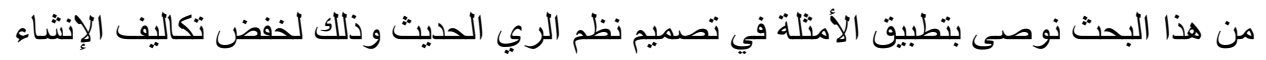

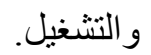

